\title{
Power System Fault Data and Time Series
}

\author{
Marinko Stojkov \\ HEP group, Distribution, Slavonski Brod, Croatia \\ Vladimir Mikuličić \\ Faculty of Electrical Engineering and Computing, University of Zagreb, Croatia \\ Srete Nikolovski \\ Faculty of Electrical Engineering, University of Osijek, Croatia
}

\section{Introduction}

Power system reliability and continuous electric power supply without downtimes or with a few as shorter as possible interruptions are basic for financial success in today's power market (EN50160). So, modern customer oriented relationships and efficient electricity service have to be included in nowadays power system management.

Reliability and availability are concept very close to electric power supply. It is based on analysing the faults on the power lines and transformer substations and maintenance during the system function in the past, managing to improve power quality in the future performance.

Maybe, the most important problem to researcher who does the power system reliability evaluation is a lack of data. Missing data are related to power lines faults, and to power customers demands and electric power flow in the system, which depend on network structure (branch connections between buses, switching states, maintenance, load characteristics), day time, seasons (average temperature) in the each faults period. These three types of power system data were estimated with more or less accuracy. This paper presents a systematic way to register some parameters of power system faults and maintenance during the time, as time series.

\section{Reliability Model}

\subsection{Markov State Space Model}

Someone who wants to do reliability quantitative estimation has to possess power system data for periods without continuous supply (history data). The reliability evaluation results would be more accurate if the monitored period is as long lasting as could be. There are a lot of techniques and mathematical models used to perform such kind of calculation. Here, the evaluation method is based on Markov state space 
model of power system components and analytical power system states enumeration approach.

Contingency enumeration approach uses a voltage existence at power system load nodes (from SCADA) to identify system deficiencies, systematically selecting all system states, looking for all interruptions which cause outage and evaluating reliability indices. Main indices of all fault events are start and end time what define time duration and amount of power load and energy (depend on daytime), making important time-series. Markov state space models are based on exponential law with time-constant failure and repair rate of each component in the network what is usual in power system reliability evaluation.

\subsection{Power System Monitoring}

Power system engineers take care about function of electric power system in all voltage levels and continually power supply for all customers. They control and monitor power system and its components and change the weakest components either during the predictive maintenance actions or after the fault occurs (more often).

The main aim is to find out the weakest link in the chain and to eliminate it before components break down, if it is possible, because it is known that the chain is as strong as the weakest link in the chain. So, the engineers try to remove the most often fault causes if it is possible, reduce number and duration of interruptions, briefly to improve power system efficiency and service.

After the data processing, attention has to be mostly paid on weak components or on important influence variables, which give important information about components deviation out of usual reliability or quality aspect borders and components lifetime.

\section{System Function Relational Data Base}

\subsection{Power System and Decision Making}

System function relational database designing is the first step in any kind of modern system analysing. If someone wants to get any conclusion about system operation or to improve results in any possible direction, he must become familiar with the system. Power system is well described with configuration (branches and buses), system states, input and output variables (demands, financial and technical laws and rules), and nowadays characteristics of deregulation and deregulated market. Also, system activities (maintenance, rebuilding, reengineering, investments), voltage problems, capacity deficiencies, branch overloads, interruption of continuity of power supply, split network problems etc. have to be well known. It is impossible to get all these system data in short period to make good business decision.

Usually, all mentioned basic data are not at the same place, or available to one or two persons. Conventional principles for decision making in high level structured power system in state ownership, on the base of insufficient data and inappropriate 
assumptions are objectively ineffective and a meter of past because of modern power market principles.

So, some kind of relational database with all or almost all-basic system data is very important precondition to solve and control technical and financial problems and to improve any above mentioned system activities.

\subsection{Power System Data Base Structure}

Relational database is sets of interdependence data describe objects, states and events in the system. Data in databank are connected and structured by the indexes, so data redundancy is completely decreased and access of data is simplified. It makes better and faster data processing and more effective information achievement. The most important problem in such complex network is trouble cause examination, and once it is known engineer can get conclusion and choose a way to solve trouble cause that direct and build future activity politics.

Database is structured in ten tables (Transformer Substation, Power Line, Failure Power Line, Maintenance, Failure Substation, Failure Component, Failure Cause, Failure Type, Power Line Location and Power Line Consume) and a number of queries. The second step of reliability evaluation is to feed database by fault data, enabling a user to do the data processing. The easiest way to do that is to monitor and write in all needed data during the normal and accident system function. After some time, it has been assumed that database is significant acceptable for further meaningful use. However, it is confidant that power system function monitor need to be permanently incorporated in every day employee's activities.

The size of databank depends on the power system that is described with, tables Transformer Substation and Power Line have as much records as there are components in the real power system. It is easy to add a new component in existed network and change present connections. The size of Failure tables and Maintenance depends on the size of system area, nowadays system equipment condition, and it is about 100-400 records per year (number of faults in whole analysed distribution power system at 10 and $35 \mathrm{kV}$ voltage levels).

Table Power Line Location defined all possible sorts of power system consume (like city, villages, farms, industry etc.), which give an information about consumers importance and shape of day load characteristics. Table Failure Type is designed on a theoretical technical source about power component faults and available SCADA signals to centre. Table Power Line Consume ease choosing of power line in the fault and simultaneously transfer number of consumers on whole power line. If the fault is isolated at the end or in the short branch of power line and it is possible to disconnect last section of power line and put the voltage on, that number must be reduced.

One of the most useful tables of database is Failure Component, which makes it possible to get information about the component quality (weak and reliable). It can be usefully used during the building activities of new part of the system by designing the system with reliable and better components. In that case, component 
manufacturer can be noticed in depth about his component disadvantages. Also, during the maintenance activities attention could be directed on weak component replacing in future period.

\section{Time series}

\subsection{Fault Duration Sequences}

Each interruption can be interpreted as time series with a several parts: preparing time (for repairing), fault location time, repairing time, fault duration time (for radial power lines) and non voltage time (for redundant city power lines). Preparing time is duration between start fault moment (start whatever by SCADA or by consumer phone call) and ready moment (maintenance-repair team is on the power line area).

\subsection{Fault Location Time and Fault Repairing Time}

Fault location time starts with end of preparing time and stops with beginning of repairing time. Here - as the first step, fault location time is difference between Duration-failure field and Duration-prepare field (for all transient faults without repair, but where power line is still in function after switching on). For all others failures above-mentioned difference is decreased by variable in database field Duration repair.

If it is power line failure in city (redundancy existent - possibility of power feed from some other substation or power line) sum of localisation time and prepare time is equal to duration of non-voltage time - because repair starts in moment when all the consumers are satisfied. So, power line failures in the city networks have not got the same duration of fields Duration failure and Duration non-voltage, the first one is greater then the second. Repairing time is important for comparing effectiveness of different teams, but attention has to be paid on the same faults types, similar components and weather conditions (rain, heat, snow, cold etc.)

The average fault location time in city area is almost a half of the same time value in the rural areas where power lines are radial. Further, the average preparing time in city area is about one third of the same variable in the rural areas, because of several reasons. Operative maintenance team can do the fault location by systematic network topology changing in city area, what is impossible in radial power lines in rural areas. Usually, city is situated in the centre of consume and rural areas are in different directions around the centre, so operative maintenance team is always in the space centre during the normal power system function.

Opposite, the average repairing time in city areas is four or five times greater then for rural areas because of underground cable long repairing time and possibility of consume feeding through the other lines. The total sum of non-voltage duration for city area is about five times less then for rural areas with the same customer number. 
Power lines are divided in sections in dependence of line switch location. Also, consumer's number and their power load are continually monitored for all switching states of power line.

\section{Reliability evaluation based on time-series}

\subsection{Real Distribution Power System}

The real fault analyses are made on the distribution power system area Slavonski Brod in Croatia. The fault duration or duration of non-voltage period is well known because of data written in load history. Contrary, power load can be only estimated. Energy Not Supplied (ENS) is calculated as a product of multiplication of average power load and time period. Since there are not existed measurements of power loads for all points in power network some approximations have to be done. Conventional approach estimation of ENS is obtained as a multiplication product of $50 \%$ of power load of all installed transformers $10 / 0.4 \mathrm{kV}$ at power lines $10 \mathrm{kV}$ and duration of non-voltage period.

Here, it is developed a new approach for estimation of ENS - power loads on fault days (after repairing) are compared with power loads of the next or previous day (according to SCADA). Attention has to be paid on the value of mean daily temperature and consume character (workday or weekend). Assumption is that power load function does not differ in a considerable value on near days in its character. Energy Not Supplied estimated until now have been overestimated due to demand for power memory effect of installed house devices and industry facilities.

\subsection{Reliability Evaluation Results}

There are important differences between achieved (new approach) and expected indices (conventional approach), especially for rural areas that are low population density parts (40-80\% depending on duration of non-voltage period). In urban areas (city), overestimation of ENS is almost neglected (5-12\%).

Power system faults analyzing for season or annual period for power lines, transformer substations or areas can be ordered by deficiency degree. Absolute and relative (on unit length) power lines faults frequencies can be easily filtered for whole distribution areas, definite transformer substations or power lines.

There are significant differences between fault types, fault causes and fault components depending on the power line age, technology and other parameters. Technology is category strict on underground or overhead power lines, voltage level and type of isolation. The other parameters are: components, soil type, soil surface shape, heights of power towers, approach possibilities (specially for trucks and hydraulic crane and platform), weather conditions, average and maximum load etc. Finally, some reliability calculations for all power lines faults are achieved performed by form (Visual Basic code): System Average Interruption Availability Index (SAIFI) is 838.6, System Average Interruption Duration Index (SAIDI) is 
666.39, Average Service Availability Index (ASAI) is 0.997 and Average Energy Not Supplied Index (AENS) is 1.47.

\section{Conclusion}

Now, it is possible to compare function modes, different maintenance and investments policy. Each of the above approaches can lead us to make conclusions or decision-making. All given information provide reasonable guidelines in system function and system state prediction in future periods, decreasing system function difficulties and solving problems in some kind of iterating process based on comparing with alternative power system. Power system reliability indices are good comparing base for power system function during the time period. Importance is exactly in possibility to mark and improve power system at any time. Also, proposed database is the basic step for making any kind of sensitivity analysis of power system function.

\section{References}

1. Billinton R., Allan R.N. Reliability Evaluation of Engineering Systems. Pitman Advanced Publishing Program Inc. Boston, London, Melbourne, 1983

2. Billinton R., Allan R.N. Reliability Evaluation of Power System. Pitman Advanced Publishing Program Inc. Boston, London, Melbourne, 1984

3. Wang L., Endreny J. Reliability techniques in large electric power systems. Academic Presss. Toronto, 1993.

4. Stojkov M., Nikolovski S., Mravak I. Improved methods of power systems availability indices determination. Safety \& Reliability ESREL, A.A.Balkema Publishers: Maastricht, 2003, pp 1503-1509

5. Stojkov M., Nikolovski S., Mravak I. The reliability evaluation of distribution power system. Safety \& Reliability ESREL, A.A.Balkema Publishers: MunichGarching, 1999, pp 341-346 